\title{
Problem Solving of Isopropyl Alcohol - Water Azeotropic Characteristics Using Packed (Natural Zeolite) Bed Adsorber
}

\author{
Laras Prasakti ${ }^{1}$, Muhammad Hartono ${ }^{1}$, Pandu Prabowo Jati ${ }^{2}$, Muhammad Fajar Setiaji ${ }^{1}$, Sang Kompiang \\ Wirawan ${ }^{1}$, and Hanifrahmawan Sudibyo ${ }^{1, *}$ \\ ${ }^{1}$ Chemical Engineering Department, Faculty of Engineering, Universitas Gadjah Mada, Jalan Grafika No. 2, Yogyakarta 55281, Indonesia \\ ${ }^{2}$ Technical Services Operation Support, PT. Chevron Pacific Indonesia, Komplek Caltex Mandau, Bengkalis, Riau 28784, Indonesia \\ *Corresponding author: hanifrahmawan.s@mail.ugm.ac.id
}

\author{
KEYWORDS \\ Adsorption kinetics \\ Natural zeolite \\ Azeotropic mixture \\ Freundlich model \\ Isopropyl-alcohol-water
}

\begin{abstract}
The adsorption kinetics of water from an azeotropic mixture of isopropyl alcohol and water using chemically activated natural zeolites with and without a binder (starch) was investigated. In addition, an investigation of the compressive strength of zeolite pellets was conducted to ascertain the performance of the adsorbent for long-term operation. Three parameters were applied in the zeolitemaking process: the particle size of zeolite $(20,30,50$, and 80 mesh), the sintering temperature (550, 750 , and $\left.1,000^{\circ} \mathrm{C}\right)$, the compaction pressure $(2,4$, and 6 tonnes), and the starch-to-zeolite weight ratio $(0,1: 3,1: 5$, and 1:7). Initial screenings indicated that the strongest zeolite pellet was 80-mesh zeolite powder (without starch addition) that was compacted using 6 tonnes pressure and was sintered at $750^{\circ} \mathrm{C}$. The adsorption tests using the strongest zeolite were conducted in a packed-bed column for three cycles, followed by compressive strength tests on the zeolite pellets after each cycle. According to the experimental data, zeolite pellets made without the addition of starch could adsorb up to $98.4 \%$ of the initial water in the mixture. From the four models proposed to describe the kinetics of adsorption of water from the mixture, the Freundlich model turned out to be the best model.
\end{abstract}

(c) The Author(s) 2020. This article is distributed under a Creative Commons Attribution-ShareAlike 4.0 International license.

\section{INTRODUCTION}

Solvent recovery is an important process in the chemical industry to make the whole process more efficient and more economical, as well as to satisfy environmental regulations. Solvent recovery can be performed by several methods. For instance, by distillation using a distillation column, by pervaporation using a membrane (Kasik and Lin 2014; Chaniago et al. 2015), and by adsorptive separation in an adsorption column (Saha et al. 2015; Nagarajan and Chandiramouli 2017). While distillation appears to be the most frequently used separation technique in industry, its separation performances are limited, especially in a case where the difference of the boiling points of each chemical species is very tight, creating an azeotrope.

Isopropyl alcohol (IPA) is one of the organic solvents widely used in industry, either as a solvent or as an additive in pharmaceuticals (Walter et al. 2016), and is frequently mixed with water. One of the problems observed in the conventional distillation of an IPA-water mixture is the presence of an azeotropic condition when the IPA purity in the mixture is $87.7 \mathrm{wt} . \%$ and when the mixture temperature is $80.3^{\circ} \mathrm{C}$ (Kuila and Ray 2013). A more efficient dehydration of IPA in industry is necessary to allow the recycling of pure IPA, to create economic benefits, and to achieve an environmentally friendly process (Liu et al. 2014).

Some modifications have been made on the distillation of azeotropic mixtures, such as by using an additional solvent to perform extractive distillation or by employing membrane distillation (Sawamura et al. 2015; Chen et al. 2017). Separation using a membrane has also begun to receive more attention from researchers, because it offers the recovery of pure IPA. Nonetheless, membrane distillation requires an expensive initial investment due to the high quality materials needed to provide high permeability, selectivity, durability, and mechanical stability. Additionally, the maintenance of the membrane by regular chemical cleaning also causes the operational expense to be costly (Hua et al. 2014). Therefore, this study focused on developing a method that was not only able to recover pure IPA, but also lowered the cost needed for separation.

In this study, adsorption was chosen as the method to be developed by utilizing chemically activated natural zeolite as an adsorbent, which was packed in a vertical cylindrical column. Natural zeolite has excellent properties for the water adsorption process because of its hydrophilic properties (Giroux et al. 2016; Siddiki et al. 2016). Compared with activated carbon, natural zeolite could have a higher surface area, up to $1000 \mathrm{~m}^{2} / \mathrm{g}$, and poses a uniform pore size distribution. However, natural zeolite that exists in nature as aluminosilicate crystalline is known to be contaminated by metal oxides attached on the pore surface (Pérez-Page et al. 2016). To allow for the attachment of water molecules to the zeolite pore surfaces, free oxides and impurities such as $\mathrm{Al}_{2} \mathrm{O}_{3}, \mathrm{SiO}_{2}, \mathrm{CaO}, \mathrm{MgO}, \mathrm{Na}_{2} \mathrm{O}$, and $\mathrm{K}_{2} \mathrm{O}$ must be removed (Bonaccorsi et al. 2016). These molecules may close the pathways into the pores or the active sites of the zeolite, causing the adsorption capacity of the zeolite 
to decrease. Therefore, the natural zeolite must be chemically activated.

The chemical activation can improve the physicochemical properties of zeolite by changing its $\mathrm{Si} / \mathrm{Al}$ ratio. The change of $\mathrm{Si} / \mathrm{Al}$ ratio results in a surface activity change (Zhang et al. 2016). A low Si/Al ratio is preferred to enhance the hydrophilic properties of natural zeolite (Veiga et al. 2017). Commonly, natural zeolite has had a relatively low $\mathrm{Si} / \mathrm{Al}$ ratio, between 5.14 and 6.65 (Yu et al. 2009). However, chemical activation using low a concentration of strong acid is still needed to remove impurities in natural zeolite (Lu et al. 2009).

Moving on from the chemical aspect to the physical aspect of zeolite, mechanical strength should also be considered to assure the sustainability of the continuous adsorption of water from the mixture in an adsorption column. In a vertical adsorption column, adsorbents could experience mechanical stress originating from the compression, tensile strain, and fluid-induced pressure, because of the height of the zeolite heap in the column. The prolonged mechanical stress experienced by the adsorbent might lead to the formation of a fragment or crack, resulting in irregularities in the fluid flow distribution and potentially reducing the adsorption capacity. Therefore, this study evaluated the compressive strength of the adsorbents constructed from different particle sizes, compaction pressures, and sintering temperatures. The effect of a natural binding agent, namely starch, on the compressive strength of the adsorbent was also investigated. Ultimately, the reusability of the adsorbent was assessed to determine the prospect of long-term operation.

After studying the effect of chemical and physical pretreatment, an adsorption kinetic model was developed to describe the mechanism of water attachment on the zeolite surface. A kinetic model is useful when the scale of the operation needs to be enlarged. In this case, scaling up from lab-scale to either pilot- or industrial-scale would need a mathematical model to ensure that the design of the process could result in the same adsorption performance.

\section{MATERIALS AND METHODS}

\subsection{Materials}

Natural zeolite was obtained from a local mine in Klaten, Indonesia. Technical-grade IPA containing a significant amount of water was purchased from Bratachem (Jakarta, Indonesia). Sulfuric acid $\left(\mathrm{H}_{2} \mathrm{SO}_{4}\right) 98 \%$ as the activating agent, starch as the binding agent, and deionized water were supplied by Sigma-Aldrich (St. Louis, United States).

\subsection{Methods}

\subsubsection{Zeolite pre-treatment}

The chemical activation of zeolite followed the same method explained in the literature (Wirawan et al. 2015),

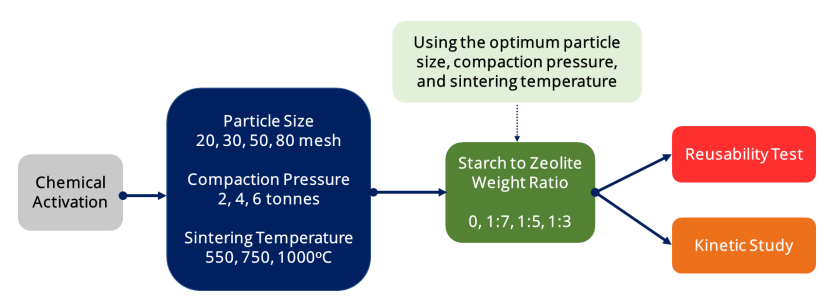

FIGURE 1. Flowchart of adsorption experimental steps. by using $0.2 \mathrm{~N}$ sulfuric acid $\left(\mathrm{H}_{2} \mathrm{SO}_{4}\right)$. The steps of the experiment in this study are illustrated in Figure 1. Chemically activated natural zeolites were screened using a sieving machine with four different screener sizes: 20, 30, 50, and 80 mesh. One zeolite pellet was produced by pressing 4-4.5 grams of screened zeolite powder in a $3 \mathrm{~cm}$ diameter cylindrical mold made of stainless steel. The pressure of the pressing machine was controlled at 2, 4, and 6 tonnes. Subsequently, the compressed zeolite pellet was sintered at three different temperatures $\left(550^{\circ} \mathrm{C}, 750^{\circ} \mathrm{C}\right.$, and $1,000^{\circ} \mathrm{C}$ ) for $2 \mathrm{~h}$ in a furnace with a heating rate of $15^{\circ} \mathrm{C} / \mathrm{min}$. Afterwards, the compressive strength test was performed on the zeolite pellet according to ASTM C39 (ASTM 2020), and the porosity of the zeolites was measured according to ASTM C138 (ASTM 2017). After the optimum particle size, compaction pressure, and sintering temperature that resulted in the highest compressive strength were identified, chemically activated zeolite was mixed with starch at starch/zeolite ratios of 0, 1:3, 1:5, and 1:7. Later, the starchzeolite mixture was transformed into adsorbent (pellet) using the optimum conditions found in the earlier step. The optimum amount of starch that could be added was also determined based on the highest compressive strength.

\subsection{Batch adsorption}

The adsorption test was conducted for $90 \mathrm{~min}$ in a packedbed column that was operated in a closed-loop circulation (Figure 2). There were 25 zeolite pellets in the column in every test. The IPA solution was flowed by a centrifugal pump from the closed reservoir into the column. The adsorption process was conducted in batch, and the concentration of the chemicals in the effluent changed over the time. The sampling process was carried out through the sampling node. Samples were taken every $5 \mathrm{~min}$. The concentration of IPA and water in the sample was analyzed using a gas chromatography-mass spectrometer (Hewlett-Packard $5890 \mathrm{GC}$ interfaced with a 5971A mass selective detector).

The zeolite pellets would be reused for two cycles $(3 \times$ $90 \mathrm{~min}$. in total). The purpose was to study the reusability performance of the zeolite. After each cycle, the adsorbent pellet was dried in an oven at $80^{\circ} \mathrm{C}$ with a heating rate of $15^{\circ} \mathrm{C} / \mathrm{min}$ for $1 \mathrm{~h}$. This drying step is to represent the regeneration of the adsorbent after it has been saturated

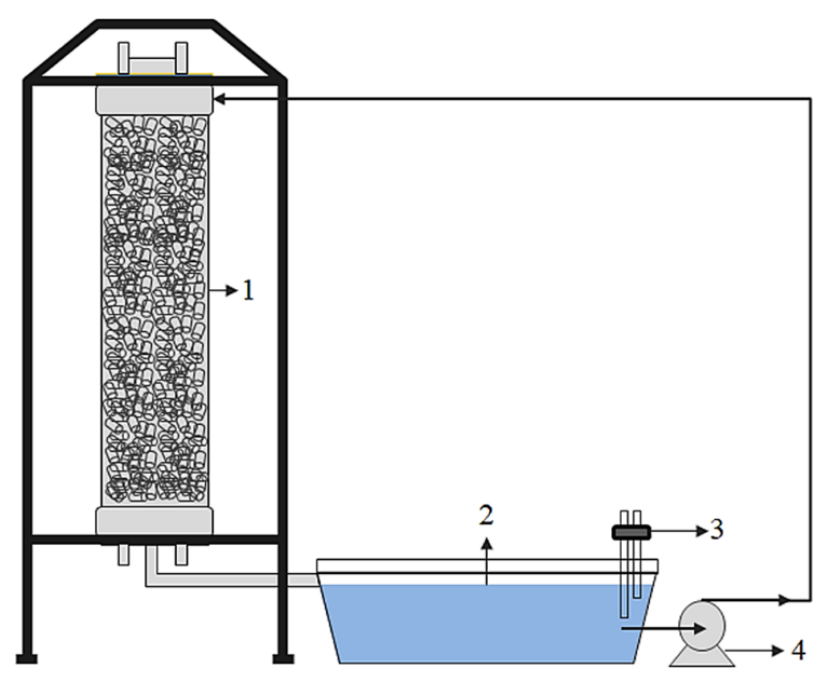

FIGURE 2. Experimental set-up for batch adsorption in a packed-bed column. 1: Packed bed column, 2: reservoir, 3: sampling equipment, 4: circulation pump. 
TABLE 1. Porosity of zeolite pellets compacted using 6 tonnes of pressure and sintered at $750^{\circ} \mathrm{C}$.

\begin{tabular}{|c|c|c|}
\hline Sample size (mesh) & Compaction pressure (tonne) & Porosity (\%) \\
\hline \multirow[t]{3}{*}{20} & 2 & 50.76 \\
\hline & 4 & 46.51 \\
\hline & 6 & 43.39 \\
\hline \multirow[t]{3}{*}{30} & 2 & 49.56 \\
\hline & 4 & 39.41 \\
\hline & 6 & 39.39 \\
\hline \multirow[t]{3}{*}{50} & 2 & 37.98 \\
\hline & 4 & 36.82 \\
\hline & 6 & 36.01 \\
\hline \multirow[t]{3}{*}{80} & 2 & 34.76 \\
\hline & 4 & 32.97 \\
\hline & 6 & 30.87 \\
\hline
\end{tabular}

with adsorbate. The compressive strength of the dry used pellet was examined using the same procedure as that for the fresh pellet before the adsorption test.

\subsection{Mathematical model}

In studying the physical phenomenon of the adsorption process, four mathematical models were assessed. The most representative model was determined by the lowest Sum of Square Error (SSE) after the experimental data was curve-fitted using the proposed models. The first proposed model was based on the film theory. Mass balance derivation under unsteady-state condition using this model resulted in Equations 1, 2, and 3.

$$
\begin{gathered}
\frac{d X_{W}}{d t}=k_{a} \cdot\left(C_{W}-C_{W}^{*}\right) \\
\frac{d C_{W}}{d t}=-k_{a} \cdot\left(C_{W}-C_{W}^{*}\right) \\
C_{W}^{*}=H \cdot X_{W}
\end{gathered}
$$

where $X_{W}$ and $C_{W}$ represent water content in the adsorbent and solution, respectively; $C_{W}-C_{W}^{*}$ represents driving force of the mass transfer of water from the solution into zeolite (mixed film theory); and $k_{a}$ represent the mass transfer coefficient. Adsorbate concentration at equillibrium $\left(C_{W}^{*}\right)$ could be calculated using the Henry constant $(H)$. The adsorption mechanism could also be modelled using the Freundlich adsorption isotherm equation (Equation 4), in which $k$ stands for the mass transfer coefficient. This was considered as the second model.

$$
\frac{d C_{W}}{d t}=k \cdot C_{W}^{n}
$$

The third model proposed was the intra-particular diffusion model (Equation 5), which states that the adsorption of molecules into the adsorbent is not affected by diffusion through the film boundary layer. The intra-particular diffusion process describes the model dependency on time and amount of water adsorbed into zeolite pores (Yu et al. 2009; Arias Arias et al. 2017).

$$
q_{t}=k_{i} \cdot t^{0.5}
$$

where $q_{t}$ accounts for milligram of water adsorbed per zeolite mass, while $k_{i}$ and $t$ refer to the intra-particular diffusion coefficient in $\mathrm{mg} /\left(\mathrm{g}\right.$ zeolite.minute ${ }^{0.5}$ ) and the adsorption time (minute), respectively.

The fourth model proposed was the fractional attainment model, representing mass ratio of adsorbed substance ( $q_{t}, \mathrm{mg} \mathrm{H}_{2} \mathrm{O} / \mathrm{g}$ zeolite) to the equilibrium amount of the adsorbed substance $\left(q_{e}, \mathrm{mg} \mathrm{H}_{2} \mathrm{O} / \mathrm{g}\right.$ zeolite). The phenomenon was formulated in the form of a mathematical equation, as shown in Equations 6 and 7 (Chaudhry et al. 2017; Tan and Hameed 2017), where $k_{p}\left(\mathrm{~min}^{-1}\right)$ is the fractional attainment constant.

$$
\alpha=\frac{q_{t}}{q_{e}}
$$

$$
\ln (1-\alpha)=-k_{p} \cdot t
$$

\section{RESULTS AND DISCUSSION}

\subsection{Zeolite pre-treatment}

Figure 3 shows the compressive strength of zeolite pellets manufactured at sintering temperatures of $550^{\circ} \mathrm{C}, 750^{\circ} \mathrm{C}$, and $1,000^{\circ} \mathrm{C}$. The compaction pressure applied in manufacturing the adsorbent influenced the compressive strength. The greater the compaction pressure, the greater the compressive strength of the adsorbent. This could be ascribed

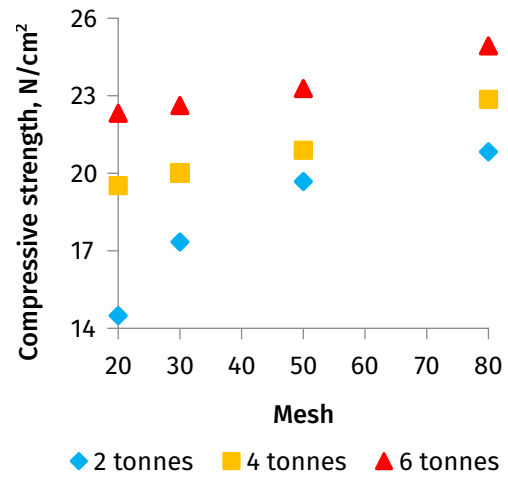

(a)

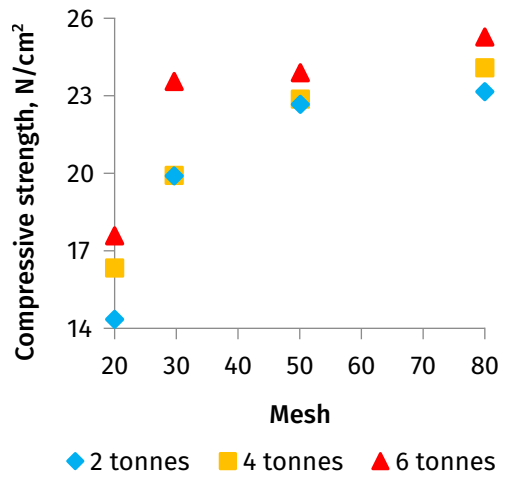

(b)

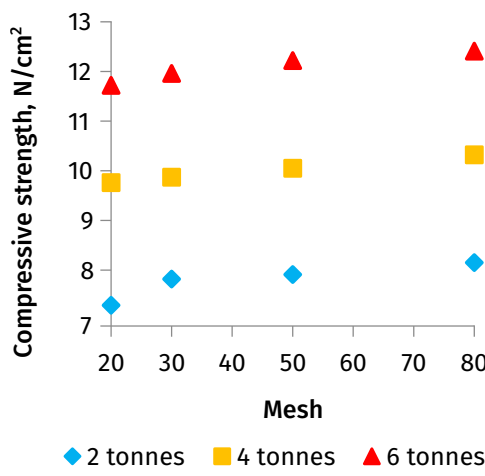

(c)

FIGURE 3. Compressive strength of zeolite pellet in relation to particle size for sintering temperature of (a) $550^{\circ} \mathrm{C}$, (b) $750^{\circ} \mathrm{C}$, and (c) $1,000^{\circ} \mathrm{C}$. 


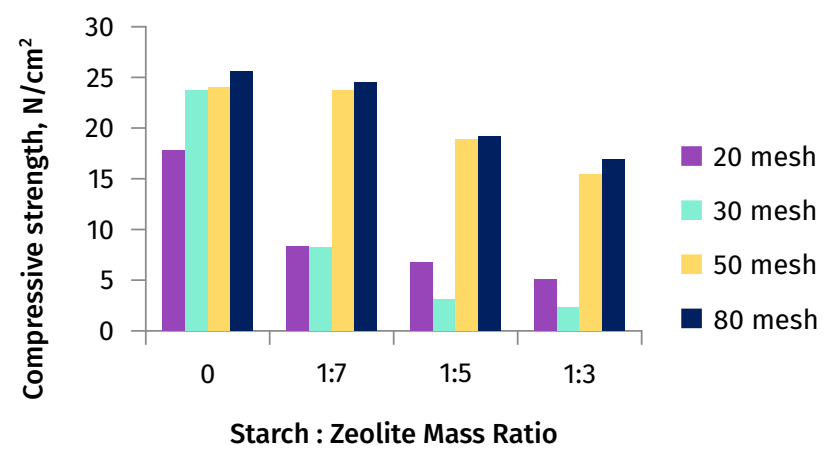

FIGURE 4. Compressive strength of zeolite pellets produced from the mixture of starch and zeolite by means of 6 tonnes pressing and calcination at $750^{\circ} \mathrm{C}$.

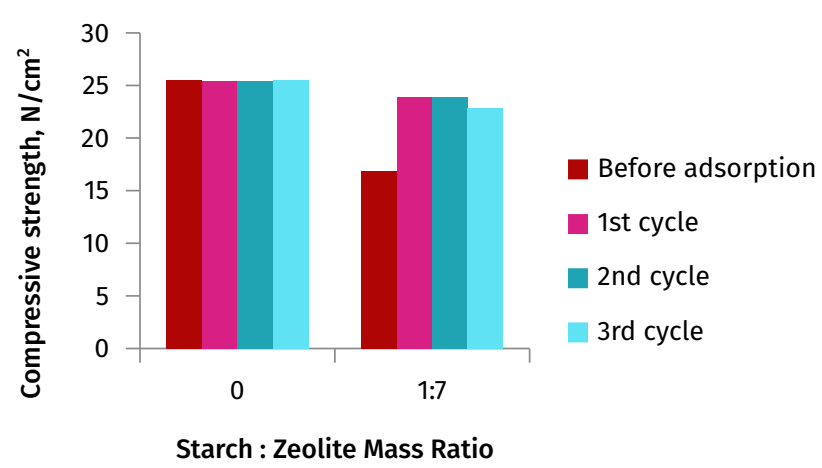

FIGURE 5. Compressive strength of non-starch zeolite pellet and starchbinded zeolite pellet (with a weight ratio of 1:7) after three cycles of adsorption.

to the greater force applied to the pressing process that reduces the porosity in the zeolite and consequently, making the zeolite pellets more solid and more resistant to pressure. The result of the porosity test on the zeolite pellets sintered at $750^{\circ} \mathrm{C}$, as shown in Table 1 , supports the explanation. The zeolite pellet with the lowest porosity (30.87\%) posed the highest compressive strength.

For the zeolite pellet sintered at $550^{\circ} \mathrm{C}$, the compressive strength value was lower than that of the pellet sintered at $750^{\circ} \mathrm{C}$. This was in accordance with the theory that the higher the sintering temperature, the stronger the bond between zeolite particles. Because of the stronger bond, the ability to resist the load given during the compressive strength test was greater and resulted in higher compressive strength. However, a uniqueness was observed for the zeolite pellet sintered at $1,000^{\circ} \mathrm{C}$. According to Figure $3 \mathrm{c}$, the zeolite pellet had relatively low compressive strength between $7-12.5 \mathrm{~N} / \mathrm{cm}^{2}$. This was possibly caused by the change of dimension during the sintering process at $1,000^{\circ} \mathrm{C}$. At that temperature, the zeolite powder could shrink and bend on the periphery of the pellet. Consequently, the surface of the zeolite pellet was uneven and

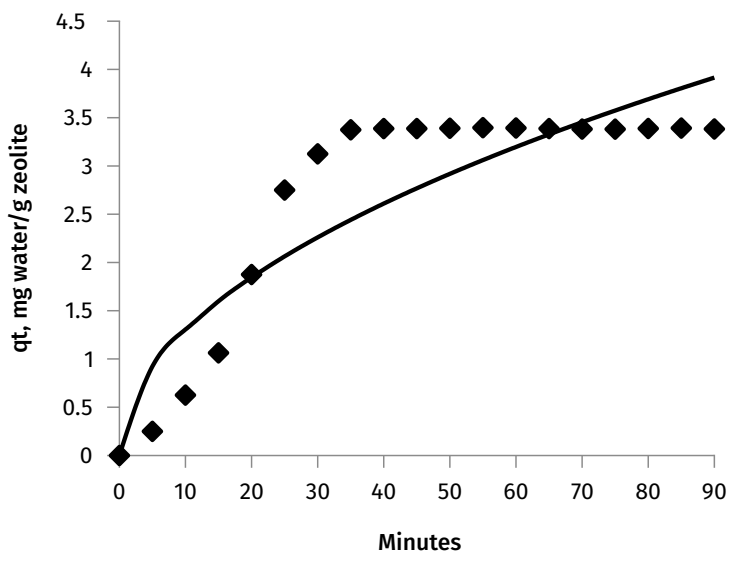

(a)

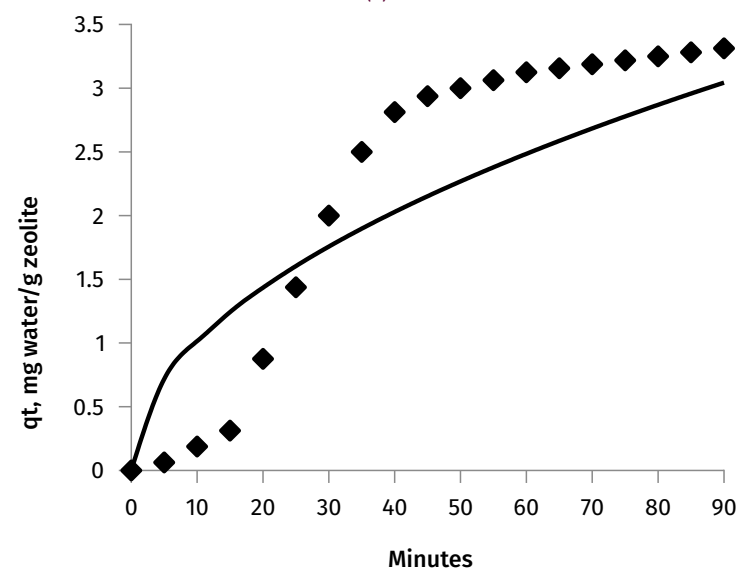

(b)

FIGURE 6. Intra-particular diffusion model: $q_{t}$ value during adsorption process using (a) non-starch zeolite pellet and (b) starch-binded zeolite pellet (-: model prediction, $\$$ : experimental data).

easily broken when loaded. Under three sintering temperatures and three compaction pressures, the highest compressive strength $\left(25.56 \mathrm{~N} / \mathrm{cm}^{2}\right)$ was given by zeolite pellet manufactured using 80 -mesh-screened zeolite, pressed with 6 tonnes pressure, and calcined at $750^{\circ} \mathrm{C}$.

Figure 4 illustrates the compressive strength of the adsorbent with and without the addition of a binding agent. The presence of starch in the pellet also did not change the trend observed in the pellet manufactured without starch, the smaller particle size of which resulted in greater compressive strength. Increasing the starch content from 0 to $12.5 \%, 16.7 \%$, and $25 \%$ decreased the compressive strength of the adsorbent. The decline in the mechanical strength of the zeolite pellets was probably caused by the destruction of amylopectin in the starch. The content of amylopectin in starch made the mixture become viscous and sticky when mixed with water. However, during the sintering process (at $750^{\circ} \mathrm{C}$ ), some of the starch present in the zeolite mixture might have been converted into char, creating a cavity

TABLE 2. Adsorption constants and SSE of every model.

\begin{tabular}{llcc}
\hline Models & Non-starch & SSE & Starch-binded \\
\hline Film theory & $\frac{d X_{W}}{d t}=0.0461\left(C_{W}-0.064 X_{W}\right)$ & 0.0508 & $\frac{d X_{W}}{d t}=0.0246\left(C_{W}-0.202 X_{W}\right)$ \\
& $\frac{d C_{W}}{d t}=0.0461\left(C_{W}-0.064 X_{W}\right)$ & 0.0508 & $\frac{d C_{W}}{d t}=0.0246\left(C_{W}-0.202 X_{W}\right)$ \\
Freundlich & $\frac{d C_{W}}{d t}=0.0272 C_{W} 0.51$ & 0.0433 & $\frac{d C_{W}}{d t}=0.0245 C_{W} 0.73$ \\
Intra-diffusion & $q_{t}=0.4127 t^{0.5}$ & 5.2466 & $q_{t}=0.3208 t^{0.5}$ \\
Fractional attainment & $\ln (1-\alpha)=-5.7215 t$ & 2.2395 & $\ln (1-\alpha)=-0.0557 t$ \\
\hline
\end{tabular}




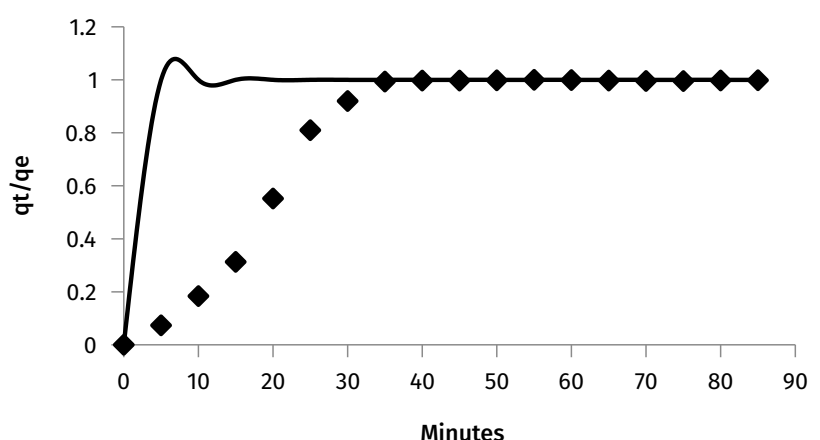

(a)

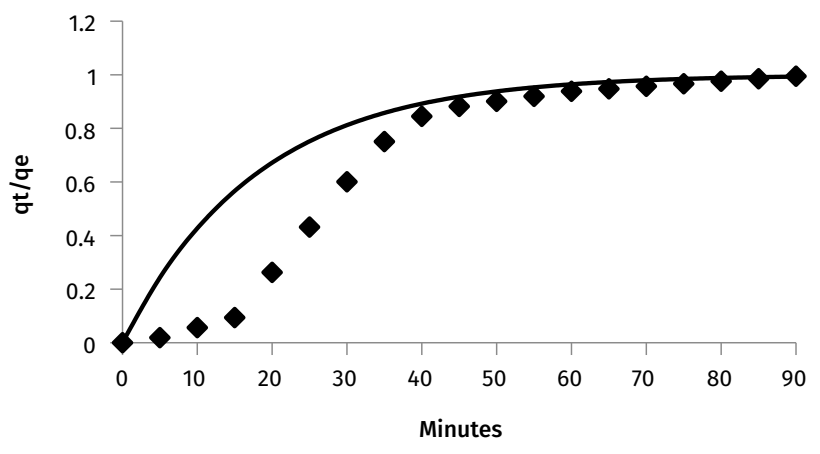

(b)

FIGURE 7. Fractional attainment model: $q_{t} / q_{e}$ value during adsorption process using (a) non-starch zeolite pellet and (b) starch-binded zeolite pellet (-: model prediction, $\diamond$ : experimental data).

in the zeolite structure. A study by (Liu et al. 2014) found that starch starts undergoing a carbonization reaction at above $500^{\circ} \mathrm{C}$, and that further heating of starch at above $600^{\circ} \mathrm{C}$ generates amorphous carbon, such as char. Thus, instead of increasing the mechanical strength of the pellet, the presence of char made zeolite increasingly fragile. This could be seen from the condition of the pellet with the starch-to-zeolite ratio of 1:5 and 1:3, which had a darker colour than pellets without starch or with lower starch content, such as that with a ratio of 1:7.

To study the reusability of zeolite pellets, the pellets that had been used after the first cycle of batch adsorption were reused for the second and the third cycle of adsorption. Due to the highest compressive strength compared with the other starch-binded zeolites, a starch-tozeolite ratio of 1:7 was used in the reusability tests. As indicated in Figure 5, starch did not make the adsorbent stronger. Moreover, the compressive strength continuously decreased after each cycle of adsorption. This might be caused by the affinity of starch to adsorb water and subsequently form a gel-like structure in the micro-scale. The drying step prior to testing in the second and the third cycle to regenerate the adsorption capacity might also contribute to the weakening of the zeolite pellet by shrinking the gel-like structure formed after the adsorption. This shrinkage might leave some void spaces in the pellet, causing the porosity to increase. As a result of greater porosity, the compressive strength consequently becomes lower.

\subsection{Batch adsorption}

Four models were tested to describe the physical phenomenon of the adsorption of water from an IPA-water mixture using natural zeolite. Figure 6 reveals the results of the intra-particular diffusion model. Based on this model, water adsorbed in the zeolite would reach a relatively con-

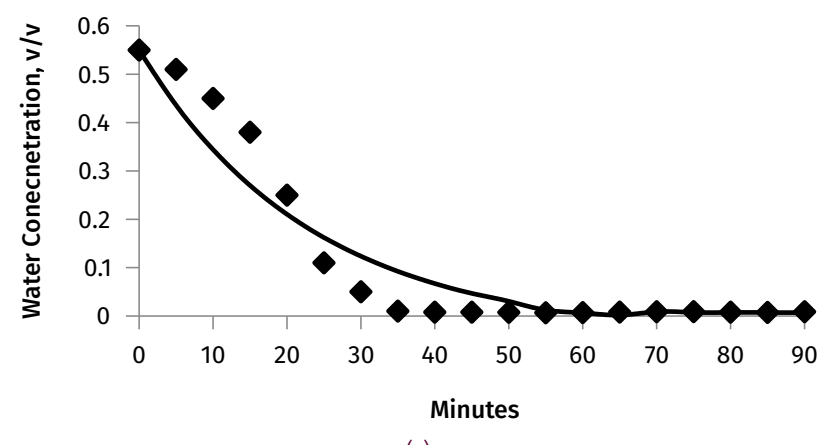

(a)

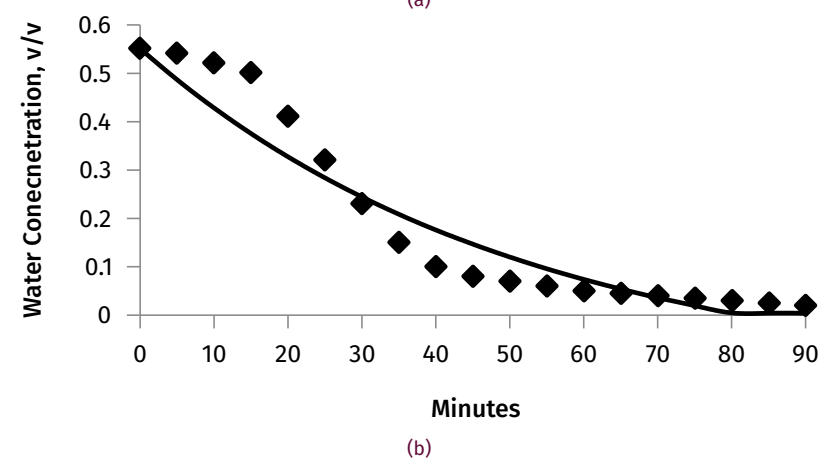

FIGURE 8. Water concentration in the effluent of adsorption column fitted with film theory kinetics model using (a) non-starch zeolite pellet and (b) starch-binded zeolite pellet (-: model prediction, $\downarrow$ : experimental data).

stant value after a certain period. The constant value of water concentration indicated a faster adsorption rate of the non-starch zeolite pellets. However, the model did not show a good representation of the experimental data, given the high SSE value, as listed in Table 2.

Figure 7 depicts the result of the fractional attainment model. It could be observed that this model was not suitable for modelling the adsorption process, although it had a lower SSE compared with the intra-particular diffusion model. The deviation showed in Figure 7 might be ascribed to the inaccurate equilibrium water molecule adsorbed value, because measurements in this experiment did not include water content inside the zeolite.

Among the four models proposed, the most representative models (visually) were the film theory and Freundlich models (Figures 8 and 9, respectively). However, based on the SSE comparison in Table 2, the Freundlich model was the most appropriate model as it had the lowest SSE value.

Another interesting finding that should be noted from Figures 8 and 9 is the different initial rate of water adsorption. From an adsorption time of 0 to 20 minutes, the adsorption rate is relatively faster for non-starch zeolite compared with starch-binded zeolite. This might imply that the driving force of the adsorption (represented by $C_{W}-C_{W}^{*}$ in Equations 1 and 2) is higher for non-starch zeolite adsorption. The higher driving force in non-starch zeolite can occur because of the lower Henry constant, so that the equilibrium concentration $\left(C_{W}^{*}\right)$ was lower, according to Equation 3. From an operational perspective, the higher adsorption rate is also beneficial because it enables smaller process equipment to used, and consequently for a smaller amount of investments to be made.

Generally, Figures 6-9 are evidence that non-starch zeolite pellet has a higher adsorption rate. One of the explanations for this is that the use of starch as a binder decreased zeolite pore activity. As previously mentioned, at $350^{\circ} \mathrm{C}$, starch started to decompose into char, which in turn would cover the active surface of the zeolite, henceforth reducing 


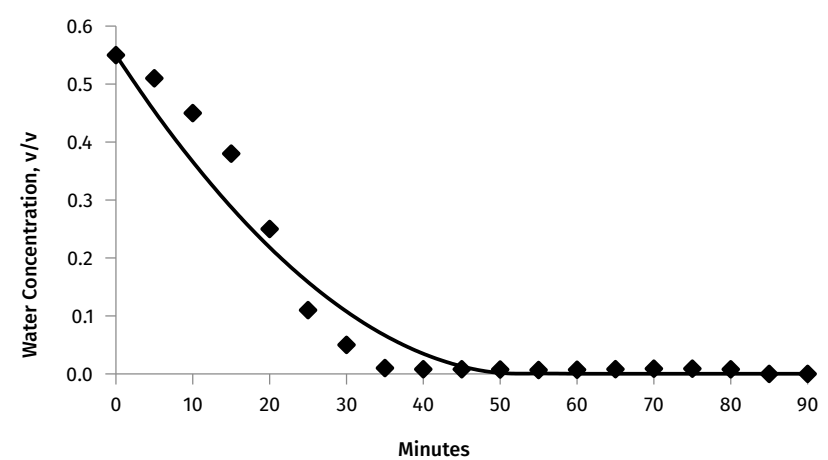

(a)

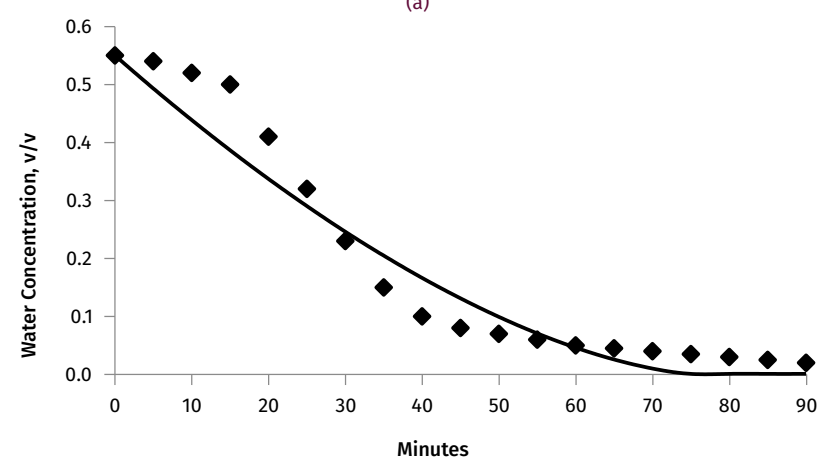

(b)

FIGURE 9. Water concentration in the effluent of adsorption column fitted with Freundlich model using (a non-starch zeolite pellet and (b starchbinded zeolite pellet (-: model prediction, $\$$ : experimental data).

the adsorption capacity of the zeolite pellet. Besides, as reflected in Figures 8 and 9, the raw zeolite could adsorb water from the IPA-water system by $98.4 \%$ of the initial water concentration, whereas the zeolite mixed with a binder could adsorb slightly less water, speficially $96.3 \%$ of the initial water concentration in 90 minutes of operation.

\section{CONCLUSIONS}

The compressive strength test revealed that raw zeolite pellet produced from zeolite powder of 80 mesh, underwent a compaction pressure of 6 tonnes, and sintered at $750^{\circ} \mathrm{C}$ exhibited the highest compressive strength $\left(25.56 \mathrm{~N} / \mathrm{cm}^{2}\right)$. The addition of starch as a natural binding agent in the pellet could not improve the physicochemical properties and the adsorptive capacity of the natural zeolite as an adsorbent. The use of natural zeolite as an adsorbent was proven effective to remove water from the IPA-water mixture by up to $98.4 \%$ using non-starch zeolite pellets. This advantage was accompanied by good reusability after being used for three cycles, along with a faster rate of adsorption. This faster rate of adsorption may provide good technical and economic feasibility in a large-scale operation. This technical-economic feasibility of large-scale operation can be evaluated by means of the Freundlich model, which explained the adsorption kinetics the best among the proposed models in this study.

\section{ACKNOWLEDGMENTS}

The authors are grateful for the financial support of Hibah Penelitian Kerjasama Luar Negeri dan Publikasi Internasional of the Indonesian Directorate General of Higher Education (DIKTI) 2013-2014.

\section{AUTHORS' CONTRIBUTIONS}

Conceptualisation: SKW, HS, PPJ, MFS; analysis and investigation: HS, MFS, PPJ; data analysis: SKW, HS, PPJ, MFS; writing and preparation of manuscript: $\mathrm{HS}, \mathrm{MH}, \mathrm{LP}$; funding acquisition: SKW. All authors have read and agreed to the published version of the manuscript.

\section{COMPETING INTERESTS}

The authors declare no conflict of interest.

\section{REFERENCES}

Arias Arias FE, Beneduci A, Chidichimo F, Furia E, Straface S. 2017. Study of the adsorption of mercury (II) on lignocellulosic materials under static and dynamic conditions. Chemosphere. 180:11-23. doi:10.1016/j.chemos phere.2017.03.137.

[ASTM] American Society for Testing and Materials. 2017. Standard test method for density (unit weight), yield, and air content (gravimetric) of concrete. West Conshohocken: ASTM International. doi:10.1520/C0138_C 0138M-17A.

[ASTM] American Society for Testing and Materials. 2020. Standard test method for compressive strength of cylindrical concrete specimens. West Conshohocken: ASTM International. doi:10.1520/C0039_C0039M-20.

Bonaccorsi L, Bruzzaniti P, Calabrese L, Proverbio E. 2016. Organosilanes functionalization of alumino-silica zeolites for water adsorption applications. Microporous Mesoporous Mater. 234:113-119. doi:10.1016/j.microm eso.2016.07.019.

Chaniago YD, Minh LQ, Khan MS, Koo KK, Bahadori A, Lee M. 2015. Optimal design of advanced distillation configuration for enhanced energy efficiency of waste solvent recovery process in semiconductor industry. Energy Convers Manage. 102:92-103. doi:10.1016/j.enconman .2015.03.086.

Chaudhry SA, Zaidi Z, Siddiqui SI. 2017. Isotherm, kinetic and thermodynamics of arsenic adsorption onto IronZirconium Binary Oxide-Coated Sand (IZBOCS): modelling and process optimization. J Mol Liq. 229:230-240. doi:10.1016/j.molliq.2016.12.048.

Chen HH, Chen MK, Chien IL. 2017. Using [EMIM][OAC] as entrainer for isopropyl alcohol dehydration via extractive distillation. Paper presented at: 6th International Symposium on Advanced Control of Industrial Processes (AdCONIP); Taipei, Taiwan. p. 257-262. doi: 10.1109/ADCONIP.2017.7983790.

Giroux M, Sahadeo E, Libera R, Maurizi A, Giles I, MarteelParrish A. 2016. An undergraduate research experience: synthesis, modification, and comparison of hydrophobicity of zeolites A and X. Polyhedron. 114:42-52. doi:10.1016/j.poly.2015.09.037.

Hua D, Ong YK, Wang Y, Yang T, Chung TS. 2014. ZIF90/P84 mixed matrix membranes for pervaporation dehydration of isopropanol. J Membr Sci. 453:155-167. doi:10.1016/j.memsci.2013.10.059.

Kasik A, Lin YS. 2014. Organic solvent pervaporation properties of MOF-5 membranes. Sep Purif Technol. 121:38-45. doi:10.1016/j.seppur.2013.04.033.

Kuila SB, Ray SK. 2013. Separation of isopropyl alcoholwater mixtures by pervaporation using copolymer membrane: analysis of sorption and permeation. Chem Eng Res Des. 91(2):377-388. doi:10.1016/j.cherd.2012.0 8.005 . 
Liu Y, Feist SD, Jones CM, Armstrong DR. 2014. Isopropyl alcohol dehydration by hot gas pressure swing adsorption: experiments, simulations, and implementation. Ind Eng Chem Res. 53(20):8599-8607. doi:10.1021/ie 500171v.

Lu S, Ma Y, Zhu C, Shen S, He Q. 2009. The effect of hydrophobic modification of zeolites on $\mathrm{CO} 2$ absorption enhancement. Chin J Chem Eng. 17(1):36-41. doi: 10.1016/S1004-9541(09)60029-X.

Nagarajan V, Chandiramouli R. 2017. Adsorption studies of alcohol molecules on monolayer MoS 2 nanosheet-a first-principles insights. Appl Surf Sci. 413:109-117. doi: 10.1016/j.apsusc.2017.04.008.

Pérez-Page M, Makel J, Guan K, Zhang S, Tringe J, Castro RH, Stroeve P. 2016. Gas adsorption properties of ZSM5 zeolites heated to extreme temperatures. Ceram Int. 42(14):15423-15431. doi:10.1016/j.ceramint.2016.06.193.

Saha BB, El-Sharkawy II, Miyazaki T, Koyama S, Henninger SK, Herbst A, Janiak C. 2015. Ethanol adsorption onto metal organic framework: theory and experiments. Energy. 79(C):363-370. doi:10.1016/j.energy.2014.11.022.

Sawamura KI, Furuhata T, Sekine Y, Kikuchi E, Subramanian B, Matsukata M. 2015. Zeolite membrane for dehydration of isopropylalcohol-water mixture by vapor permeation. ACS Appl Mater Interfaces. 7(25):13728-13730. doi:10.1021/acsami.5b04085.

Siddiki SM, Toyao T, Kon K, Touchy AS, ichi Shimizu K. 2016. Catalytic hydrolysis of hydrophobic esters on/in water by high-silica large pore zeolites. J Catal. 344:741-748. doi:10.1016/j.jcat.2016.08.021.

Tan KL, Hameed BH. 2017. Insight into the adsorption kinetics models for the removal of contaminants from aqueous solutions. J Taiwan Inst Chem Eng. 74:25-48. doi:10.1016/j.jtice.2017.01.024.

Veiga PM, Gomes AC, Veloso CO, Henriques CA. 2017. Acid zeolites for glycerol etherification with ethyl alcohol: catalytic activity and catalyst properties. Appl Catal, A. 548(July):2-15. doi:10.1016/j.apcata.2017.06.042.

Walter V, Pfeuffer B, Hoffmann U, Turek T, Hoell D, Kunz U. 2016. Heterogeneous reactive extraction for isopropyl alcohol liquid phase synthesis: microkinetics and equilibria. Chem Eng Sci. 155:175-185. doi:10.1016/j.ces.20 16.08.005.

Wirawan SK, Sudibyo H, Setiaji MF. 2015. Development of natural zeolites adsorbent: chemical analysis and preliminary TPD adsorption study. J Eng Sci Technol. (3):87-95.

Yu Q, Zhang R, Deng S, Huang J, Yu G. 2009. Sorption of perfluorooctane sulfonate and perfluorooctanoate on activated carbons and resin: kinetic and isotherm study. Water Res. 43(4):1150-1158. doi:10.1016/j.watres.2008. 12.001.

Zhang Y, Hirata A, Nakasaka Y, Tago T, Taniguchi T, Masuda T. 2016. Effects of crystal morphology, Si/Al ratio and thickness of an MTW zeolite membrane on water/2propanol separation by pervaporation. Microporous Mesoporous Mater. 222:178-184. doi:10.1016/j.microm eso.2015.09.021. 